\title{
A Study of Textless Back Translation from the Perspective of Intertextuality
}

\section{— Taking the Woman Warrior: Memoirs of a Girlhood Among Ghosts as an example}

\author{
Wei Cai ${ }^{1, a}$ \\ ${ }^{1}$ Beijing Normal University, Beijing, 100875, China \\ ${ }^{a}$ cuxcaiwei@163.com

\begin{abstract}
Textless back translation is a new phenomenon of back translation, which refers to the process of translation of a text describing the content of the national culture without a specific original or a process of translating the original text into a foreign language. This study focuses on the study of this special type of translation and evaluates the translation process from a theoretical perspective. Guided by the theory of intertextuality translation, this paper adopts the categorization of explicit intertextuality (allusion, parody, hybridity and quotation) and structural intertextuality proposed by Fairclough, and discusses the cases in the context of textless translation in two parts. From the perspective of intertextuality and intercultuality, this paper tries to verify the theoretical conception of textless back translation, including the standard of language, style standard and cultural standard, as well as the ultimate model of textless back translation.
\end{abstract}

Keywords: textless back translation, intertextuality, translation

\section{AN OVERVIEW OF TEXTLESS BACK TRANSLATION}

Back translation generally refers to the process of retranslating a text translated into a particular language back into the source language. Compared with the naming of forward translation, back translation is often used to test the quality of translation, to evaluate the effect of translation teaching, and to assist translation studies, even language studies. Due to the development of the study of bilingual writers, Chinese-American writers and sinologists abroad, the research related to back translation has become more and more popular.

Textless back translation refers to the process of translation of texts describing the cultural content of a nation directly written in a foreign language without a specific original text or original text translated into a foreign language. The conceptual understanding of textless back translation originated from the discussion of scholar Wang Hongyin. Lin Yutang wrote the English novel "Moment in Peking" abroad, and when Wang studied his Chinese version, he proposed that such a text with Chinese culture as its subject matter and content was "cultural return", but there was no translation on the basis of the original text, so it was not" language return ". He called this phenomenon as "root-less back translation" which later was revised as "textless back translation". Although this kind of translation lacks" original works", it just lacks a specific text as a basis, and still has a cultural foundation. Through the concept of "textless back translation", it includes a series of text types, including the works of Chinese-American writers, bilingual Chinese-translated works, and the Chinese translation works of Sinologists at home and abroad. It can be seen that the concept of textless back translation is on the culture based, which aims to reveal some commonalities in the translation process of works containing culture based content. Therefore, the in-depth study of the phenomenon of textless back translation is helpful to guide the translation practice of such works. 


\section{THE THEORETICAL FRAMEWORK--- THE PERSPECTIVE OF INTERSEXUALITY}

Inspired and influenced by the theory of "intersubjectivity" and "intertextuality" in the West, the study of "inter " has become a hot topic in the field of cultural research and its scope has been expanding and the phenomenon like interculturality also appears. The intertextual perspective plays an important role in the study of the referential relationship in textless back translation, so this study is mainly based on the intertextual theory.

\subsection{The content of intertextuality theory}

Intertextuality theory usually refers to the study of the referential relationship between two or among more texts. Intertextuality includes the referential relationship between two specific texts. The theory of intertextuality is of great significance, which induces and emphasizes a universal literary phenomenon.

The theory of intertextuality was first put forward by Julia Kristeva, a French literary theorist. Based on the polyphonic novels and the carnival discourse of literature proposed by Bakhtin, Kristeva analysed in depth and clarified the concept of intertextuality. She put forward that when the relationship between "author and reader" coincided with that between "text and context", one word or text was a reproduction of other words or texts. On this basis, Roland Barthes, a French literary theorist, further elaborated and popularized the theory of intertextuality. Michael Riffaterre made intertextuality a theory based on the interpretation of the recipient, and held that the relationship between the reader and the work played a leading role in intertextuality. Gerard Genette completed the transition of the concept of "intertextuality" from a broad to a narrow sense, thus transforming intertextuality from a linguistic concept to a literary one.

\subsection{Expression forms and techniques of intertextuality}

In the study of intertextuality, scholar Luo Xuanmin combed out the expression forms and techniques of intertextuality, and thought that different categories of intertextuality should be fully described, and the expression forms and techniques of intertextuality should also be distinguished. From the perspective of intertextual theory, Fairclough pointed out that the expression forms of intertextuality can be divided into manifest intertextuality and constitutive intertextuality, which manifested the intertextuality more intuitively.

Specifically, the manifest intertextuality refers to the superficial features of a text and the traces of the intertextuality between the text and other texts or texts directly discovered by the reader according to common sense and reading experience in the process of text reading. Luo believes that the four main forms of the manifest intertextuality are: quotation, allusion, parody and hybridity. Quotation refers to a reference to the writings of other authors and other references. Parody, in the Collins English Dictionary, has the following meaning: "to express a familiar situation or character in a humorous or an exaggerated way, or to write, play, or music by imitating the style of a well-known writer". The feature of parody is that the reader can identify the objects, of the parody in a certain way, either for amusement, out of negative mentality or appreciation. It can be seen that the parody intends to use classical texts as a means to achieve satire or other artistic effects. Allusion is to quote allusion. Allusion has its special national or national literary background, which is generally a story or a historical fact. Therefore the allusion's source is generally religion, folklore, famous historical event and some classical literature works and so on. Allusion makes the text content concise and concrete, the euphemistic and implicit. Hybridity refers to the three relatively narrow forms of expression: mosaic, idiom and the proverb. Hybridity can cover a wide range of expression forms including poem, couplet, doggerel, tongue twister, and various kinds of idioms and proverbs, which are directly embedded in literary texts and enhance the receptivity of literary works.

Compared with manifest intertextuality, the expression of constructive intertextuality is more indirect, it is not the reference relation between the text and the specific text or text, but the intertextual reference relation between the text and the previous text in terms of genre, type and even subject, which can be found by the reader in the course of reading. Because in literature, cultural factors such as philosophy, customs and religious ideals are also an integral part, which makes the interpretation of literary works must be based on the complete cultural context of an era. Extend the connotation of constructive intertextuality, so that cultural texts can be included in it, and the intertextuality reference in the phenomenon of textless back translation has more abundant meaning and is more close to the purpose of this research.

\subsection{An intertextual study in translation}

In China, the first paper to study translation from the perspective of intertextuality is "Intertextuality and Translation" published by Yang Yansong, which mainly discusses the guidance of intertextuality to translation practice, and the choice of appropriate translation strategies according to the different intertextuality, namely, quotation, borrowing and enlightenment. On this basis, Jiang Xiaohua discussed the meaning and origins of some words with diachronic and aggregated concept of intertextuality in order to provide guidance for the choice of translation strategies and perfect the translation. Both of them paid attention to the role of intertextuality on 
concrete translation practice, which made the intertextuality theory enter into the domestic translation field. On the basis of combing the intertextuality theory of different western schools and sketching the evolution intertextuality thought in China, Luo Xuanmin summarized the three criteria of intertextual translation relevance criterion, neutralization criterion and economy criterion, thus clarifying the requirements of intertextual on translation practice.

In a word, the paradigm of applying intertextuality theory to the paradigm of translation studies has its depth and systematicity after the frontier of intertextuality translation studies has been excavated. It is a general trend to introduce the perspective of intertextuality into the study of specific translation types in order to guide specific translation practice. As a special type of translation, textless back translation has certain representativeness.

\section{ANALYSIS FROM THE RESPECTIVE OF INTERTEXTUALITY}

\subsection{The analysis of manifest intertextuality}

According to the common forms and means of expression of intertextuality, manifest intertextuality such as quotation, allusion, parody and hybridity is more common in literary texts, so this paper mainly chooses the novel Woman Warrior as the focus of case analysis. The Woman Warrior: Memories of a Girlhood among Ghosts is the first work by the Chinese-American writer Kingston, M H. This book is a must-read bibliography of contemporary American literature, which combines personal life experience with a large number of Chinese myths, literary classics and folklore borrowed and rewritten in a way of storytelling, and combines tradition and reality to reflect the moral and material indignation, confusion and struggle of Chinese Americans. As a representative work of Chinese-American literature and under the background of a large number of Chinese culture, The Woman Warrior is published in English and translated into various countries in the world. In 1998, it was first translated into Chinese and published in China. The process of retranslating Woman Warrior into Chinese is a typical example of textless back translation.

\subsubsection{Allusion}

Allusion, with the cultural accumulation and typical national cultural characteristic, is widely used in the Chinese and Western literature works, and also appears in the textless back translation of literature class works. The allusions used in The Woman Warrior are as follows:

Original text: "My mother relished these scare orgies. She was good at naming -Wall Ghost, Frog Spirit (frogs are "heavenly chickens"), Eating Partner. She could find descriptions of phenomena in ancient writings-the
Green Phoenix stories, "The Seven Strange Tales of the Golden Bottle," "What Confucius Did Not Talk About." She could validate ghost sightings."

Target text: “母亲就愿意讲这些吓人的故事。她起 名字很有两下子——墙头柜、蛙精 (蛙被称为“天鸡” ）、饿死鬼。她确实能从古书中找出这类描写, 例如 她能用《聊斋》里的《青凤传》和黄钧宰所撰写的作 品《金壶七墨》以及袁枚的《子不语》等故事来证实 鬼的存在。”

This passage is from the third chapter of the country doctor (Shaman), mainly about that the mother Yonglan believes in ghosts, but is not afraid of ghosts, and even helps students exorcise ghosts. The introduction of ancient whimsical novels to prove the existence of ghosts shows that Yonglan firmly believes it. The result of the literal translation of Green Phoenix Story refers to the Qingfeng (which means "green phoenix" in Chinese), a story from Strange Stories from a Chinese Studio. It tells the love story of Geng Sheng and the fox spirit named Qingfeng. The literal meaning of "What Confucius Did Not Talk About" means the content of Confucius' silence. It should be from the note-taking essay What Confucius Did Not Talk About written by Yuan Mei in the Qing Dynasty, which means "Confucius does not speak of gods or ghosts" and the content is mainly about "some things exciting people to hear about". The literal meaning of "Seven Strange Tale of Golden Bottle" is the seven oddities of a golden bottle. As a novel of note-taking novel written by Huang Junzhai in the Qing Dynasty, The Golden Pot and the Seven Ink recorded what he saw and heard during the tour, including some anecdotes, which is more contextual. As far as the context is concerned, it is a very typical use of allusion to illustrate the existence of ghosts by citing the literary works with strange stories. But the intertextual effect and translation of this text are quite different when it comes to the readers, because there is no green phoenix from beginning to end. And if it is translated as "Green Phoenix Story", it will make people regard it as a story about a green phoenix. There are many differences in the translation of "Confucius does not speak of gods or ghosts" in many classical versions of The Analects of Confucius, and we can see that there are many versions of The Analects of Confucius, and it is difficult to form a fixed form of expression (idiom). Compared with the Chinese readers, who only need to derive "What Confucius Did Not Talk About" from the Analects of Confucius to obtain the intertextual effect, the Western readers need to consider more than one version and spend more time and energy to get the same intertextual effect. The author uses a typical intertextual approach, but it is difficult to achieve results, and such an approach should be intended by the author. This gap from the use of allusion is visible to the naked eye, but also exists for a long time. In the translation of Strange Stories from a Chinese Studio, Giles encountered this conundrum that these works contain "numerous allusions and adaptations 
of stories in previous literature"; "sometimes the story goes smoothly, but the next moment suddenly becomes an incomprehensible text, whose meaning is connected with historical references and allusions that can only be understood if they are industrious in the study of all kinds of annotations or other reference books. But this is not an unsolved problem. In his notes, Giles devoted a great deal of effort to covering as many different areas of Chinese culture as possible, as well as trying to eliminate the strangeness and estrangement of Chinese culture to Western readers.

Here, the figurative metaphor "ghost" is used to describe the cultural identity dilemma of ChineseAmericans and women on the edge of society and culture. Because of this, Kingston, $\mathrm{M} \mathrm{H}$. in the use of the allusion, deliberately selected strange stories not known to Westerners, in order to create a sense of cultural separation. From the respective of maxim of relevance the context effect of the translation is much more effective than that of the original, because in the translation of The Woman Warrior, the context effect is greatly enhanced, which hinders the original intention of using allusion to create strange feeling and estrangement. Moreover, from the respective of economy criterion, too much background information weakens the expression intention and the language is not direct and accurate enough. The sense of heterogeneous created at the cultural level have disappeared to such a degree that it is difficult to reproduce the intertextual effects of the original text.

\subsubsection{Parody}

In the use of parody, The Woman Warrior is draw lessons from the image of "Hua Mulan" image. In Chapter 2, "White Tiger", "I" heard my mother tell stories and imagined myself as "Fa Mu Lan":

Original text: "We'll use this great hall for village meetings," I announced. "Here we'll put on operas; we'll sing together and talk-story." We washed the courtyard; we exorcised the house with smoke and red paper...Wearing my black embroidered wedding coat, I knelt at my parents-in-law's feet, as I would have done as a bride. "Now my public duties are finished," I said. "I will stay with you, doing farmwork and housework, and giving you more sons.'

Target text: “这个大厅就用作村会堂吧。”我说, “唱 戏、唱歌、讲故事。”我们用水冲洗了院子, 焚纸燃香, 祛除屋里的邪气...... (我) 换上黑色刺绣的婚礼服, 我像新娘那样趾在公婆面前。“国事已毕, ”我说“我要 守在你们身边耕耘纺织, 生儿育女。”

This paragraph describes the glorious return of Hua Mulan, her eradication of rural bullies, and her return to see her parents-in-law plot. In translation, four-word phrases such as "burning paper to burn incense", "ploughing and weaving" and "giving birth to children" are often used, but in reference to the original text, there are many differences. There are only "giving you more sons", and there are no" childbearing girls". As the above analysis shows, the original author consciously creates the heterogeneous text, which can also be seen in the description of this paragraph. "Burning paper to burn incense" is generally used for sacrifice, not cleaning houses; only mentioning "giving you more sons" is to emphasize the importance of women in the family succession; and "black embroidered wedding clothes" changed into, according to verification, it was the wedding dress shape which was more popular in the Zhou Dynasty. These transplants and deformation is just for the purpose of parody heterogeneous context. From the perspective of relevance criterion, the intertextuality of the original text is determined from the beginning of writing Chinese fairy tales to western readers; however, the deletion of the translation reduces the effort in the process of derivation, that is, the reader does not need to think about why it is "red paper" nor does "living children" need to be associated with the old tradition of inheriting generations, thus enhancing the degree of relevance and pushing the original author's intention to the opposite.

\subsubsection{Hybridity}

Hybridity is to put the real text directly into the creation of the work without modification, so that the discourse in the text can be mutually different, but in terms of the content of the work, it is more receptive. The hybridity discussed here is mainly the intertextuality effects of some customs or used texts in literary works. In The Woman Warrior, there are many Chinese proverbs:

Original text: "Any merchant who advertises 'Honest Scales' must have been thinking about weighting them," she says. Many sellers displayed the sign "Children and Old Men Not Cheated."

Target text: “任何吹嘘自己不”短斤少两”的生意人 都一定是想在秤上做手脚的人。”她说。不少生意人 都挂着块牌子, 上写“童叟无欺”。

According to the concrete performance of the hybridity technique, we can find that there is not much change when we put the realistic things into the literary works. However, the discourses appear to be incomprehensible to the written words of the original narration, which leads to the mutual difference and is more likely to arouse the reader's association and resonate with the readers from the view of the real life. The case also has the deeper enlightenment to the use of the hybridity technique in the textless back translation, and its "the unaltered reality" shows that the source of things need to have evidence, or at least accord with the reader's expectation of some kind of perspective, which will attract the reader's sense of view. That is to say, for 
proverbs and so on, there are no objective conditions for transplant and modification. And in the use of these real texts, there is generally no change, so the process of back translation seems easier.

\subsubsection{Quotation}

In the process of textless back translation, the quotation of foreign language works mostly involves the history and culture of the country, which is applied to all types of texts, and the intertextual effect of the quoted works is most intuitive.

Original text: They told the students that they would begin with a text as old as the Han empire, when the prescription for immortality had not yet been lost. Chang Chung-ching, father of medicine, had told how the two great winds, yang and yin, blew through the human body.

Target text: 他们说我们要从汉朝的书读起, 因为 那时长生不老之方还不曾失传。医学界的先驱张仲景 提出阴阳辩证之说。

This section depicts a mother going to a medical school to study medicine. "Prescription for immortality" means the recipe for immortality; "yang and yin" means the theory of yin and yang.

In this kind of text writing, the original author does the same thing by himself when quoting material, or borrowing someone else's translation. As James J. Y. Liu points out in the Chinese Theories of Literature, all Chinese citations in this book are translated into English by him, but ready-made translations are usually used when quoting works from other Western languages. Moreover, the translations of these citations are all manifest translations, more intuitive and easily perceived by the reader than such intertextual devices as allusion, parody and hybridity. Most importantly, the use of citations makes the reappearance of the original text interspersed in works by means of textless back translation, aiming at serving the author's intention and also making the reader have a sense of substitution, without erasing the original author's intention to write in a foreign language. Therefore, although some citations make the text mixed with the reproduction of the original text, the nature of the text has not changed, the text is still textless back translated, otherwise it cannot be counted as the original author's creation.

\subsection{Constructive Intertextuality}

Constructive intertextuality is different from manifest intertextuality. As can be seen above, manifest intertextuality is clearly marked in the reading text, and the reader can find the traces regarding text or discourse. Compared with manifest intertextuality, constructive intertextuality is more recessive.
The characteristics of textless back translation of literature are mainly embodied in genre. In the novel genre, the narrative structure of many novels translated by means of textless back translation is in a sense the inheritance of Chinese cultural elements---chapter novels. The Woman Warrior is divided into five chapters, which constitute a whole. Sections and chapters are independent, with a chapter as a complete story, including the story about "I", "mother", and also "little aunt", so just reading a chapter you can still understand its content. But there is a combination between the chapters, with the growth of a Chinese-American girl as the main line, in line with the characteristics of the chapter body; moreover, the story in each chapter is interspersed with small narratives, mixed with Chinese mythology, history and imagination and in the structure of the accumulation of characteristics. In addition, in each story, the narrator plays an important role, telling the story and even describing the inner activities of the characters, which is to retain the storyteller narrative remains. Therefore, there is no tendency to approach the form and characteristics of the classical novel in the translation of The Woman Warrior. It is divided into five parts according to the structure of the original text, supplementing some chapter names, such as "White Tiger", which is translated into “白虎山 寻道”, and weakening religious contents, such as "Shaman", which is translated into “乡村医生 (Village Doctor)". In addition, there is not much structural change so the translation does not consciously imitate the characteristics of the Chinese classical novel. When exploring the reasons, we cannot deny the limited features of the text, which makes the translator difficult to grasp and even to detect it in the process of translation. It can be seen that, after the introduction of constructive intertextuality into translation, there is a higher requirement for grasping the genres, themes, types and cultural text contents of the original text.

\section{CONCLUSION}

In the phenomenon of textless back translation, the original text has some relations with Chinese cultural classics, historical legends and so on by using the form and technique of manifest intertextuality such as allusion, parody, hybridity and quotation, and the original text also has some relations with Chinese traditional literary forms in expression form of constructive intertextuality such as genre. In order to achieve the same intertextuality effect as the original text, we must adopt similar intertextuality path, search the original reference from Chinese culture and ancient books, and then deal with it properly according to the need of the original text. The intertextuality effect of the translation is greatly influenced by the translator's grasp of the original author's intention, which will affect the translator's reduction of language and culture. 
Intertextuality is universal in translation, and the theoretical value of intertextuality in translation deserves the attention of the academic circle. Moreover, translation activities help the interaction of different cultures, which is also beneficial to the local culture. This phenomenon can reveal the process from cross-cultural communication to cultural integration, analyse and restore native and foreign characteristics, and also reveal the cause and process of cultural misreading. The study of the phenomenon of textless back translation plays an important role in cross-cultural communication. Therefore, the study of the operation mechanism and the evaluation standard, the consideration of the intercultural and intertextual nature of the textless back translation, and the investigation of the intercultural interaction in the process of textless back translation should be further studied.

\section{REFERENCES}

[1] Tiphaine Samoyault. Intertextuality Studies. Tianjin: Tianjin People's Publishing House, 2003.

[2] Luo Xuanmin. Intertextuality and Translation, Lingnan University, 2006.

[3] Kingston, M H. The Woman warrior.Guilin: Lijiang Publishing House, 1998.

[4] Kingston, M H. The Woman Warrior: Memoirs of a Girlhood among Ghosts. New York: Random House, 1976.

[5] Pu Songling. Strange Stories from a Chinese Studio. Trans. By Herbert Allen Giles, London: Thos.de la Rue, 1880.

[6] Sun Yimin. English Publishing in Modern Shanghai and Cross-cultural Communication of Chinese Classical Literature (1867-1941). Shanghai: Shanghai Classics Publishing House, 2014.

[7] Wei Jingyi. The Chinese Story in the Western Context. Hangzhou: China Academy of Art Press, 2002.

[8] Liu Ruoyu (James J. Y. Liu). Theory of Chinese Literature. Nanjing: Jiangsu Education Publishing House, 2006.

[9] Yang Chun. "The Woman Warrior": From Mulan's Revenge to Cai Yan's Singing, Foreign Literature Studies, 2004, 03:74-79.

[10] Wang Hongyin. Introduction to Literary Translation Criticism. Beijing: China Renmin University Press, 2009.

[11] Zhang Fang. A Review of Back Translation Study: Review, Current Situation and Prospect. Jiangsu Foreign Language Teaching and Research, 2013, 01:81-84.
[12] Yang Yansong. Intertextuality and Translation. Chinese Translators Journal, 1994, 4:10-13.

[13] Wang Yukuo. Appreciation of American Novels in the 20th Century. Shanghai: Shanghai Foreign Language Education Press, 2010. 